\title{
Sistema Eletrocinético para Desaguamento de Rejeitos Provenientes da Mineração
}

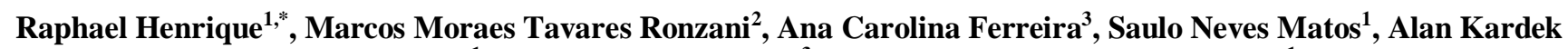 \\ Rêgo Segundo $^{1}$, Lucas Deleon Ferreira ${ }^{3}$, Paulo Marcos de Barros Monteiro ${ }^{1}$
}

\author{
${ }^{I}$ Departamento de Controle e Automação (DECAT), Escola de Minas, Universidade Federal e Ouro Preto (UFOP), Morro do \\ Cruzeiro, 35400-000 Ouro Preto, MG, Brasil. \\ ${ }^{2}$ Instituto Tecnológico Vale (ITV), Avenida Juscelino Kubitschek, 31, Bauxita, 35400-000 Ouro Preto, MG, Brasil. \\ ${ }^{3}$ Departamento de Enenharia Urbana (DEURB), Escola de Minas, Universidade Federal e Ouro Preto (UFOP), Morro do \\ Cruzeiro, 35400-000 Ouro Preto, MG, Brasil. \\ *(Tel: +55(19) 99686-8021; e-mail: raphael.engh@gmail.com).
}

\begin{abstract}
The separation of water from iron ore tailings has become one of the most important issues for mining companies, due to the decommissioning dam duty. This paper presents the electrokinetic separation method, as well as an automatic drive circuit for the system, to optimize the dewatering process. The circuit is based on a voltage regulator controlled via PWM (Pulse Width Modulation) and is used to automatically apply an electrical voltage gradient to an electrokinetic cell, aiming for constant dewatering. During the tests, we evaluate the dewatering provided by two different drive forms: applying a constant and an intermittent voltage to the cell. In addition, we present the perspectives of future work to control the voltage and current applied to the cell.
\end{abstract}

Resumo: A separação da água do rejeito proveniente do minério de ferro vem se tornando um dos temas mais importantes para as empresas mineradoras, devido ao dever de descomissionar barragens. Neste trabalho, apresenta-se o método de separação eletrocinético, bem como um circuito de acionamento automático para o sistema, com a finalidade de otimizar o processo de desaguamento de água. O circuito é baseado em um regulador de tensão controlado via PWM (Pulse Width Modulation), usado para se aplicar um gradiente de tensão elétrica em uma célula eletrocinética de maneira automática, almejando um desaguamento constante. Durante os ensaios, avaliou-se o desaguamento gerado por duas formas de acionamento diferentes: aplicando-se uma tensão constante e uma tensão intermitente à célula. Por fim, são apresentadas as perspectivas de trabalhos futuros para se realizar o controle de tensão e corrente aplicados à célula em malha fechada.

Keywords: Dams Decommissioning; Electrokinetic Method; Ore Tailings Dewatering.

Palavras-chaves: Descomissionamento de Barragens; Método Eletrocinético; Desaguamento de Rejeito de Minério.

\section{INTRODUÇÃO}

Nos processos da mineração brasileira, o minério é transcorrido por etapas úmidas para seu melhor aproveitamento, gerando rejeitos que, atualmente, são dispostos em barragens (Portes, 2013).

Com os problemas ambientais ocorridos com a disposição de rejeitos em barragens no Brasil, empresas do ramo minerador juntamente com as áreas de geotecnia das universidades, estão pesquisando novas técnicas de adensamento e desaguamento desses materiais úmidos, proporcionando maior segurança às barragens.

De acordo com Guimarães (2011), as separações sólidolíquido, como as operações de espessamento e filtragem, são processos de desaguamento para a recuperação da água e a operação da polpa restante. O espessamento é uma operação de sedimentação dos sólidos por gravidade, resultando em uma polpa de partículas no fundo do reservatório. Já a filtragem é um processo em que o rejeito num meio filtrante permite a passagem do líquido e retem a passagem dos sólidos. No entanto, ambos os processos são pouco eficazes para o desaguamento do líquido, pois o primeiro gera uma polpa ainda muito aquosa, e o segundo envolve um processo mais complexo, pois é necessário alguma operação anterior, como o espessamento ou ciclonagem, para garantir um teor mínimo de sólidos. Além disso, vale ressaltar que os filtros perdem a eficiência no decorrer do desaguamento, sendo inevitável trocá-los.

Com o intuito de promover novos métodos e expandir a área geotécnica, Ferreira (2016) desenvolveu um equipamento denominado célula eletrocinética, que permitiu explorar os 
conceitos do processo de eletrodesaguamento, em consequência do fenômeno de eletrodrenagem (Branco, 1978). Basicamente o fenômeno consiste na movimentação de um resíduo aquoso saturado com cátions e ânions, devido a aplicação de um campo elétrico, que dependendo da intensidade pode ser capaz de desassociar a água do resíduo.

Assim, neste artigo busca-se aprimorar o sistema de acionamento da célula de eletrocinese desenvolvida por Ferreira (2016). Na Seção 3 são explicados o funcionamento do projeto atual e de um projeto elaborado para o acionamento do sistema. Em seguida, na Seção 4, são apresentados os resultados obtidos em ensaios, utilizando um rejeito proveniente da mineração de minéro de ferro e bauxita. Por fim, nas Seções 5 e 6, são apresentadas as conclusões e as recomendações para trabalhos futuros.

\section{OBJETIVOS}

\subsection{Objetivos Gerais}

O principal objetivo deste trabalho é otimizar o desaguamento de água de um resíduo derivado da mineração, por meio da aplicação de um gradiente elétrico de tensão em dois eletrodos, dispostos nas extremidades da célula.

\subsection{Objetivos Específicos}

Os objetivos específicos deste trabalho compreendem as seguintes etapas:

- Desenvolver um sistema de alimentação de energia para o equipamento (célula eletrocinética), visando tensões elevadas e, consequentemente, uma maior eficácia no processo de desaguamento;

- Avaliar a influência do gradiente elétrico (75, 100, $150 \mathrm{~V} / \mathrm{m}$ ) no processo de desaguamento /adensamento eletrocinético;

- Analisar os efeitos promovidos pela técnica da tensão intermitente $(2 / 1 ; 3 / 1,5 ; 4 / 2$ - minutos ligado/minutos desligado);

- Aprimorar o sistema regulador de tensão proposto por Ronzani (2018), elaborando uma lógica de controle automático da tensão, responsável por induzir uma vazão constante no processo de desaguamento;

- Analisar a técnica de tensão contínua no desaguamento eletrocinético. Nesse processo são avaliadas as consequências da aplicação de um valor constante de tensão elétrica, visando uma maior eficiência no desaguamento.

\section{METODOLOGIA}

A célula desenvolvida por Ferreira (2016) é constituída principalmente por: (i) por dois eletrodos que recebem o gradiente elétrico de tensão; (ii) suportes para os eletrodos, duas válvulas de drenagem de água nas extremidades da célula; e (iii) quatro sensores de tensão que amostram, em um software supervisório, a tensão em diferentes distâncias entre os eletrodos.

O projeto da célula, de forma esquemática, e o supervisório podem ser observados nas Figuras 1 e 2, respectivamente.

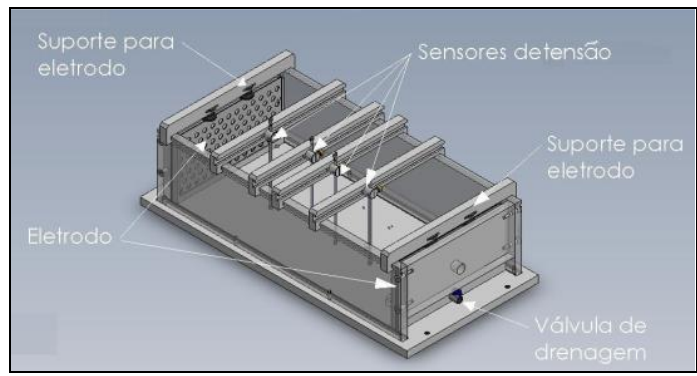

Figura 1: Esquemático da célula eletrocinética Fonte: (FERREIRA, 2016)

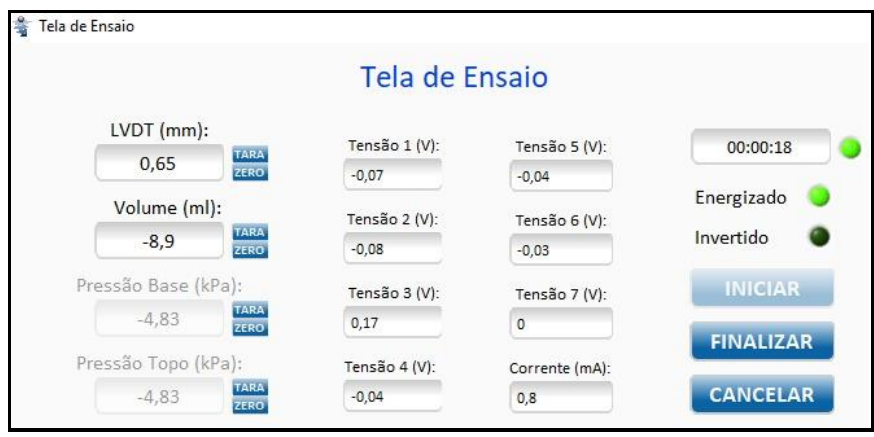

Figura 2: Sistema de supervisão de dados

Para realizar um ensaio, inicialmente realizou-se a caracterização do rejeito de minério de ferro ou bauxita, em que o teor de sólidos e a presença de argilas minerais que afetam a capacidade de troca catiônica são variáveis relevantes para o transporte de partículas sob o efeito da eletrocinética. Em seguida, realizou-se a montagem da célula, de acordo com o desenho esquemático da Figura 1. Após a inserção do material na célula, o sistema eletrônico é ativado e a válvula de drenagem é aberta, dando início ao experimento. A cada tempo predeterminado, é captado manualmente o volume de água proveniente do desaguamento até que essa porção de água seja quase nula, encerrando-se o experimento.

Atualmente o sistema elétrico é composto por uma fonte externa de $32 \mathrm{~V}$, que energiza o sistema e alimenta os eletrodos da célula eletrocinética. O sistema também é capaz de realizar as configurações do experimento, como a aplicação de tensão intermitente ou contínua. No entanto, apesar desse sistema possuir acionamento eletrônico, as leituras de vazão e a regulagem de tensão na fonte externa são ajustadas manualmente, sem nenhum tipo de controle automático. 
Para solucionar essa limitação, foi elaborado um circuito regulador de tensão no software Proteus, de acordo com o diagrama apresentado na Figura 3 e o esboço em 3D da Figura 4. Esse circuito recebe a alimentação de uma fonte externa de $32 \mathrm{~V}$ e um sinal PWM de uma placa Arduino MEGA2560. O sinal PWM passa por um filtro passa-baixa $\mathrm{RC}$, transformando-o em um sinal de tensão constante, que varia de 0 a $5 \mathrm{~V}$ de forma proporcional à variação do ciclo de trabalho do PWM. Esse sinal é amplificado pelo amplificador operacional LM324, na configuração não inversor, e aplicado ao terminal de referência do regulador de tensão ajustável LM317. Logo, a tensão de saída do circuito, aplicada aos eletrodos da célula eletrocinética, pode ser controlada, de forma automática, por meio do sinal PWM fornecido pelo Arduino.

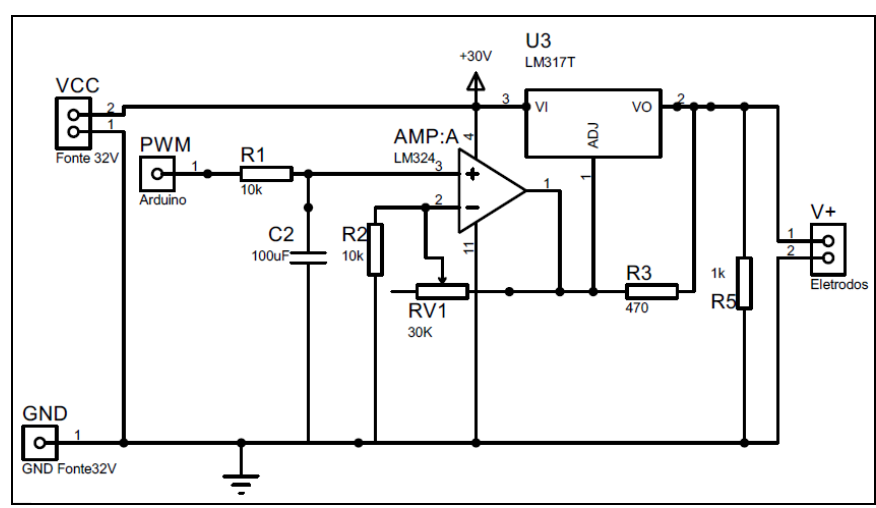

Figura 3: Circuito regulador de tensão

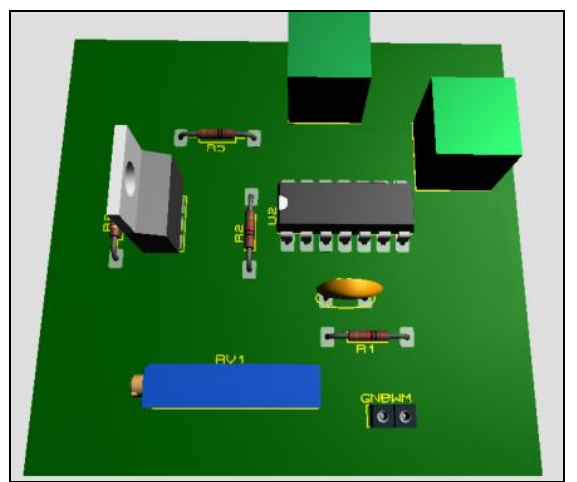

Figura 4: Placa 3D do circuito regulador de tensão

Com um código de programação na IDE da plataforma Arduino, é possível estabelecer as configurações do pino PWM do microcontrolador. Assim, de acordo com o decréscimo da vazão, aumenta-se o estado ativo (porcentagem) do duty cycle, como apresentado na Figura 5. Logo, eleva-se a tensão média de alimentação da placa reguladora e, consequentemente, aumenta-se o gradiente de tensão aplicado nos eletrodos.

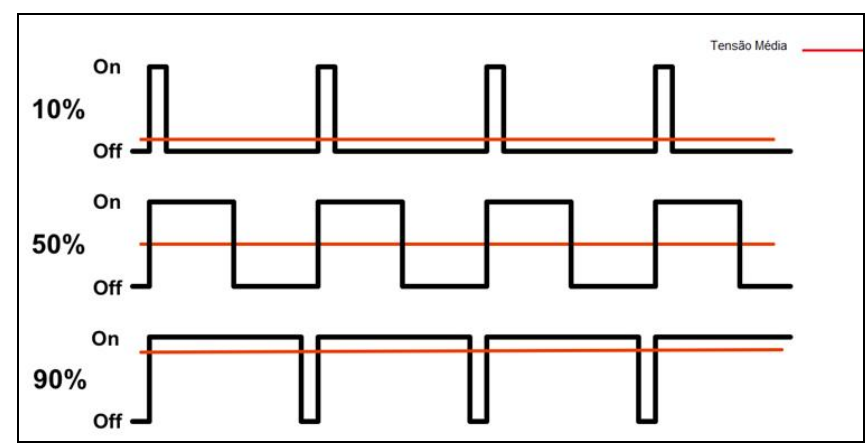

Figura 5: Funcionamento do duty cycle do PWM

\section{RESULTADOS}

Utilizando o sistema atual, o gráfico obtido em ensaios aplicando gradientes de tensão de 75, 100 e $150 \mathrm{~V} / \mathrm{m}$, é ilustrado na Figura 6, de cada gradiente pelo tempo. Nesse gráfico é possível visualizar que, quanto maior a tensão aplicada, maior é o volume drenado por hora, validando a técnica da eletro-drenagem em rejeitos advindos da mineração.

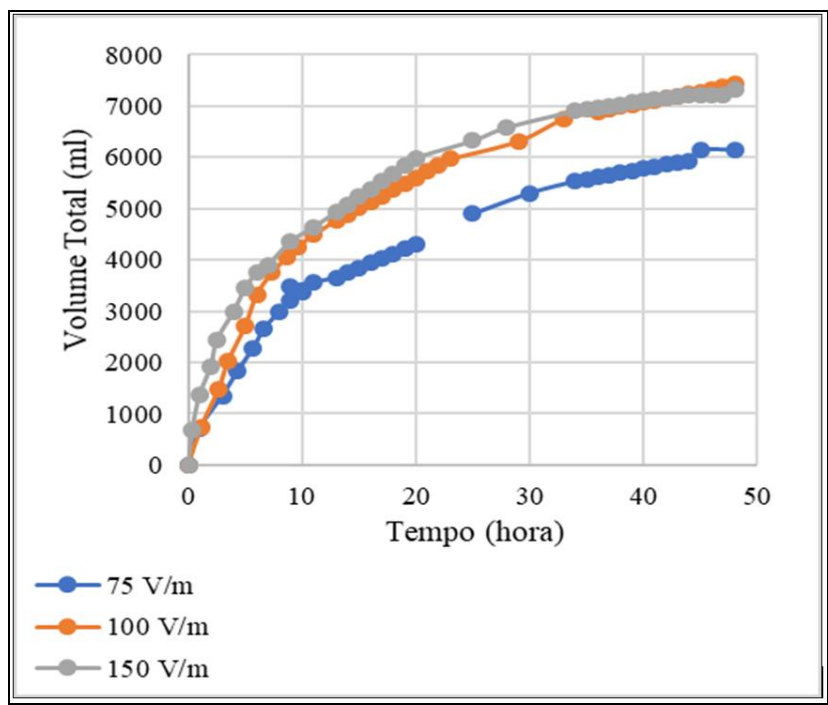

Figura 6: Curvas do volume total drenado

Se for empregado o sistema com a placa reguladora de tensão sem controle automático, não haverá mudança em relação à Figura 6, já que o sistema manteria o gradiente de tensão constante o ensaio inteiro, mas com o controle automático, é suposto que haveria um aumento de volume total drenado no tempo, além da inclinação da curva ser mais retilínea, com sua extremidade até superando $8000 \mathrm{ml}$ drenadas, pois com o declínio do volume escoado, aumentaria a tensão aplicada.

Umas das outras técnicas para eficiência da drenagem de água, é a aplicação da tensão elétrica intermitente, que seria alternar entre a ativação da tensão e seu desligamento. $\mathrm{Na}$ Figura 7, representa-se o gráfico do volume drenado ao longo do tempo, com as curvas de três configurações de tensão 
intermitente: Ensaio 1 (2 minutos ligado e 1 minuto desligado); Ensaio 2 (3 minutos ligado e 1,5 minutos deligado); e Ensaio 3 (4 minutos ligado e 2 minutos desligado).

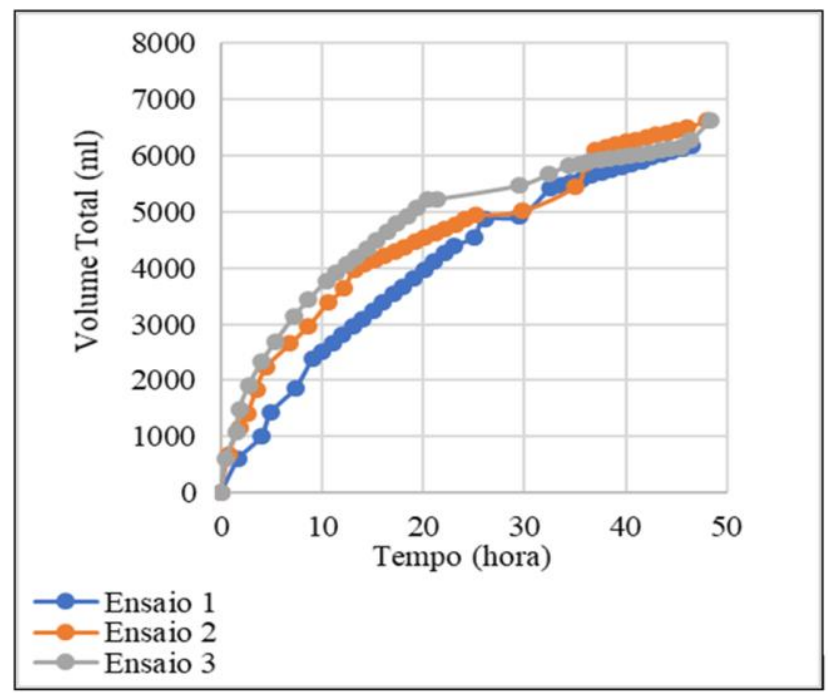

Figura 7: Curvas do volume drenado com tensão intermitente

Aplicando a técnica de tensão elétrica intermitente é possível visualizar que, apesar das curvas serem diferentes, no final dos ensaios o volume drenado é semelhante, tendo potencial para outra pesquisa em relação ao gasto energético

Como o sistema apresenta uma tensão constante, e com o decorrer do ensaio o desaguamento eleva a porcentagem de sólidos, a resistência do rejeito aumenta e, consequentemente a corrente decaí para valores menores que $50 \mathrm{~mA}$, como visto na Figura 8.

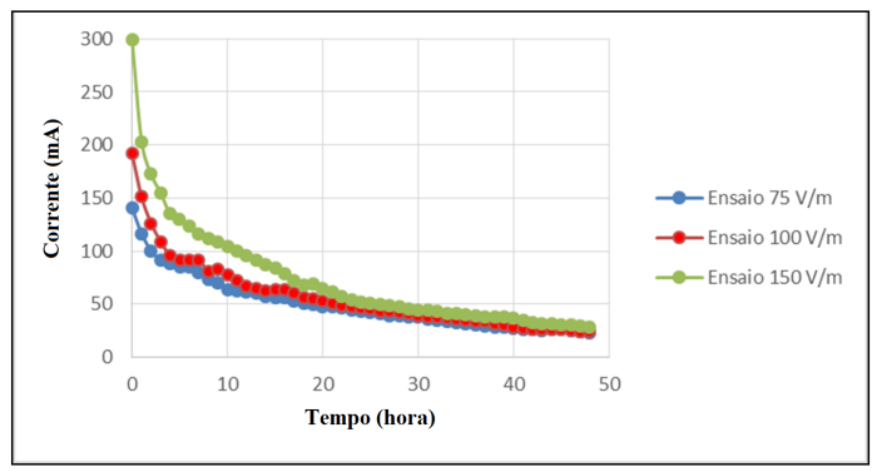

Figura 8: Curvas da corrente elétrica ao longo do tempo

\section{CONCLUSÃO}

Este artigo demonstrou a relevância do projeto da célula eletrocinética para a área de geotecnia, mais especificamente para o descomissionamento de barragens, apresentando resultados eficazes ao se aplicar um gradiente elétrico de tensão em uma porção de rejeito advindo da mineração.
Também foi proposto um sistema de acionamento automático da tensão aplicada aos eletrodos da célula, visando a otimização do desaguamento.

\section{TRABALHOS FUTUROS}

Em trabalhoso futuros, pretende-se desenvolver um controlador de vazão, em malha fechada, para o sistema. Para isso, a vazão será medida indiretamente por meio de um sensor de nível de coluna de água proveniente do desaguamento, pois a célula de pequeno porte construída por Ferreira (2016) apresenta vazão muito baixa, da ordem de $\mathrm{ml} / \mathrm{h}$, o que dificulta a realização da medição por meio de um sensor de vazão convencional.

Além disso, pretende-se investigar se corrente elétrica é uma variável relevante, pois na implementação do método eletrocinético em um complexo minerador, é fundamental ter uma análise detalhada das variáveis envolvidas. Para isso é proposto, como projeto futuro, o desenvolvimento de um sistema que controle de vazão baseado na corrente elétrica aplicada à célula, ao invés da tensão.

O sistema terá como base o amplificador operacional OPA549, um componente de baixo custo, com limiar de 0 a 10 A e entrada para sinal de controle. Assim, a tensão será uma variável livre, e a corrente uma variável que dependerá da vazão de água do desaguamento.

\section{AGRADECIMENTOS}

Os autores gostariam de agradecer ao professor Lucas Deleon Ferreira, da Universidade Federal de Ouro Preto, pela contribuição e apoio ao projeto, bem como à empresa Vale, pelo financiamento e fornecimento de material para os ensaios.

\section{REFERÊNCIAS}

Castello Branco, J. E. (1978). Estudo da eletro-osmose em solos finos. Dissertação mestrado, Universidade Federal do Rio de Janeiro, Rio de Janeiro.

Ferreira, L. D. (2016). Desenvolvimento de Equipamento de Laboratório para Estudo de Fenômenos Eletrocinéticos no Processo de Adensamento de Residuos de Mineração. Dissertação doutorado, Universidade Federal de Ouro Preto, Ouro Preto.

Guimarães, N. C. (2011). Filtragem de rejeitos de minério de ferro visando à sua disposição em pilhas. Universidade Federal de Minas Gerais, Belo Horizonte.

Portes, A. M. (2013). Avaliação da disposição de rejeitos de minério de ferro nas consistência polpa e torta. Dissertação mestrado, Universidade Federal de Minas Gerais, Belo Horizonte.

Ronzani, M. M. (2018). Desenvolvimento de um Sistema de Controle em uma Célula de Adensamento/Desaguamento Eletrocinético de Rejeitos de Mineração. Dissertação mestrado, Universidade Federal de Ouro Preto, Ouro Preto. 